\title{
Time Series Fuzzy pada Peramalan Konstribusi Pengeluaran Konsumsi Rumah Tangga terhadap PDRB Kabupaten Majene
}

\author{
Muhammad Abdy*1, Sukarna ${ }^{2}$, Rahmawati ${ }^{3}$ \\ ${ }^{1,2}$ Jurusan Matematika FMIPA UNM Makassar; ${ }^{3}$ Jurusan Matematika FMIPA Unsulbar \\ e-mail: *1.
}

\begin{abstract}
Abstrak
Time series fuzzy adalah metode peramalan yang didasarkan pada kerangka teori himpunan fuzzy. Metode ini dapat digunakan untuk peramalan dengan data historis bernilai linguistik. Dalam paper ini dibahas konsep dasar time series fuzzy beserta dengan algoritmanya. Pada bagian akhir paper ini, diberikan ilustrasi penerapan time series fuzzy dengan menggunakan data konstribusi pengeluaran konsumsi rumah tangga terhadap PDRB kabupaten Majene.
\end{abstract}

Kata kunci-Time series fuzzy, Konstribusi konsumsi rumah tangga, Data historis bernilai linguistik

\section{PENDAHULUAN}

Time series fuzzy merupakan suatu metode peramalan dalam statistika yang didasarkan pada kerangka teori himpunan fuzzy. Model ini digunakan untuk peramalan dengan data histori yang mempunyai nilai-nilai linguistik. Metode ini telah banyak digunakan diberbagai bidang untuk peramalan data dinamik dan data nonlinear (Lee, M. H, Efendi, R, Ismail, Z., 2009). Diantaranya peramalan index saham (K. Huarng, 2001, H-K. Yu, 2005, T.A Jilani \& S.M.A. Burney, 2008, C.H. Cheng, T.L. Chen \& C.H. Chiang, 2006, K. Huarng, Tiffany H-K Yu \& Yu W-S, 2007, T.H.K. Yu \& K.H. Huarng, 2008, H.H Chu, T.L. Chen, C.H. Cheng \& C.C., Huang, 2009), peramalan masalah keuangan (C.H.L.Lee, A.Liu \& W.S.Chen, 2006), masalah iklim (S.M. Chen, 2000), dan sebagainya. Konsep time series fuzzy pertama kali diperkenalkan oleh Song dan Chissom (Q, Song \& B. S. Chissom, 1993). Mereka menggunakan persamaan relasi fuzzy, dalam hal ini komposisi max-min, yaitu $A_{i}=A_{i-1} \circ R$ untuk mengkonstruksi konsep yang dibangunnya. Akan tetapi metode yang digunakan oleh Song dan Chissom memerlukan perhitungan yang panjang dan rumit untuk mendapatkan relasi fuzzy R. Kemudian Chen (S.M. Chen, 1996) memperbaiki kelemahan model Song dan Chissom dengan menyerderhanakan perhitungan aritmetika untuk memperbaiki operasi komposisi dan memperkenalkan grupgrup logika fuzzy untuk memperbaiki prediksi. Berbagai modifikasi yang lain dari model Song dan Chissom telah banyak dilakukan. Xihao dan Yimin (2008) memperkenalkan average based length dalam menentukan panjang interval untuk menaikkan akurasi ramalan. Ramli, dkk. (2018) menggunakan jarak ukuran similariti pusat gravity untuk menentukan error dari peramalan. Kemudian berbagai artikel mencoba mengubah bentuk himpunan fuzzy pada data histori dengan menggunakan bilangan fuzzy segitiga dan bilangan fuzzy trapezoid (Basyigit, A. I, Ulu, C, Guzelkaya, M, 2014, Mutalib, S. M, Ramli, N, Daud, M, 2018)

Dalam paper ini, model time series fuzzy Chen dengan beberapa modifikasinya digunakan untuk memprediksi persentase konstribusi pengeluaran konsumsi rumah tangga terhadap PDRB kabupaten Majene setiap tahunnya. Dalam bagian kedua paper ini, diberikan konsep time series fuzzy, kemudian bagian selanjutnya diberikan langkah-langkah dalam time series fuzzy, dan bagian terakhir diberikan contoh penggunaanya dengan menggunakan data persentase konstribusi pengeluaran konsumsi rumah tangga terhadap PDRB kabupaten Majene (BPS Kab. Majene) 
https://jurnal.unsulbar.ac.id/index.php/saintifik

\section{KONSEP DASAR TIME SERIES FUZZY}

Sebelum mendefinisikan time series fuzzy, terlebih dahulu diberikan definisi dasar himpunan fuzzy, sebagai berikut:

Misalkan $S$ adalah suatu himpunan semesta, yaitu $S=\left\{s_{1}, s_{2}, \ldots, s_{n}\right\}$. Suatu himpunan fuzzy $\tilde{A}_{i}$ dalam himpunan semesta $\mathrm{S}$ didefinisikan sebagai $\tilde{A}_{i}=\left\{\left(s_{1}, \mu_{A_{i}}\left(s_{1}\right)\right),\left(s_{2}, \mu_{A_{i}}\left(s_{2}\right)\right), \ldots,\left(s_{n}, \mu_{A_{i}}\left(s_{n}\right)\right)\right\}$, dimana $\mu_{A_{i}}$ adalah fungsi keanggotaan himpunan fuzzy $\tilde{A}_{i}$ dan $\mu_{A_{i}}\left(s_{k}\right)$ merupakan derajat keanggotaan $s_{k}$ dalam himpunan fuzzy $\tilde{A}_{i}$, $k=1,2, \ldots, n$. Selanjutnya didefinisikan time series fuzzy sebagai berikut (Song and Chissom, Chen S.M, Tsaur):

Definisi 1. Misalkan suatu subset dari R, yaitu $Y(t)(t=\ldots, 0,1,2, \ldots)$, adalah suatu himpunan semesta dimana himpunan fuzzy $\tilde{A}_{i}$ didefinisikan. Jika $F(t)$ merupakan koleksi dari himpunan fuzzy $\tilde{A}_{i}$, maka $F(t)$ merupakan time series fuzzy (TFS) yang didefinisikan pada $Y(t)(t=\ldots, 0,1,2, \ldots)$.

Dari definisi tersebut, $F(t)$ dapat dipandang sebagai suatu variabel linguistik dan $\tilde{A}_{i}$ nilai-nilai linguistik yang mungkin dari $F(t)$.

Definisi 2. Misalkan $F(t)$ hanya disebabkan oleh $F(t-1)$, maka relasi model orde-pertama $F(t)$ dapat dinyatakan sebagai $F(t)=F(t-1) \circ R(t, t-1)$ dimana $R(t, t-1)$ adalah matriks relasi yang menggambarkan relasi fuzzy antara $F(t-1)$ dan $F(t)$, dan $\circ$ adalah operator max-min.

Relasi antara $F(t)$ dan $F(t-1)$ dinyatakan dengan $F(t-1) \rightarrow F(t)$, relasi logik fuzzy antara $F(t)$ dan $F(t-1)$ didefinisikan sebagai berikut:

Definisi 3. Misalkan $F(t)=A_{i}$ disebabkan oleh $F(t-1)=A_{j}$, maka relasi logik fuzzy dinyatakan sebagai $A_{i} \rightarrow A_{j}$

Misalkan suatu relasi logik fuzzy yang diperoleh dari keadaan $A_{k}$ untuk suatu $k$ tertentu, maka transisi yang dibuat ke keadaan lain $A_{j}, j=1,2, \ldots, n$, dinyatakan sebagai $A_{k} \rightarrow A_{1}, A_{k} \rightarrow A_{2}, \ldots, A_{k} \rightarrow A_{n}$. Relasi logik fuzzy ini dikelompokkan kedalam suatu kelompok relasi logik fuzzy, yang ditulis sebagai $A_{k} \rightarrow A_{1}, A_{2}, \ldots, A_{n}$

Definisi 4. Misalkan $F(t)$ suatu TSF. Jika untuk sebarang $t, F(t-1)=F(t)$ dan $F(t)$ hanya mempunyai elemen yang hingga, maka $F(t)$ disebut TSF time-invarian. Selain itu disebut TSF time-varian.

\section{PROSEDUR MODEL TIME SERIES FUZZY}

Prosedur time series fuzzy dapat didefinisikan langkah demi langkah sebagai berikut (Chen, S. M)

Langkah 1: Menentukan data historis

Langkah 2: Definisikan himpunan semesta $S$ dari data histori, yaitu $S=\left[D_{\min }-D_{1}, D_{\max }+D_{2}\right] . D_{\min }$ dan $D_{\max }$ berturut-turut adalah nilai data terkecil dan nilai data terbesar dari data historis, dan $\mathrm{D}_{1}, \mathrm{D}_{2}$ nilai tertentu.

Langkah 3: Mempartisi $\mathrm{S}$ ke dalam interval-interval $u_{1}, u_{2}, \ldots, u_{n}$ yang sama panjang. Penentuan panjang interval dapat menggunakan aturan average based length (Xihao and Yimin, 2008)

Langkah 4: Definisikan himpunan fuzzy $A_{1}, A_{2}, \ldots, A_{n}$ pada himpunan semesta $\mathrm{S}$. Himpunan fuzzy ini menyatakan variabel linguistik. Himpunan fuzzy $A_{i}$ dapat didefinisikan sebagai berikut:

$A_{1}=\left\{\left(u_{1}, 1\right),\left(u_{2}, 0.5\right),\left(u_{3}, 0\right), \ldots,\left(u_{n}, 0\right)\right\}$ 
$A_{2}=\left\{\left(u_{1}, 0.5\right),\left(u_{2}, 1\right),\left(u_{3}, 0.5\right),\left(u_{4}, 0\right), \ldots,\left(u_{n}, 0\right)\right\}$

$A_{3}=\left\{\left(u_{1}, 0\right),\left(u_{2}, 0.5\right),\left(u_{3}, 1\right),\left(u_{4}, 0.5\right), \ldots,\left(u_{n}, 0\right)\right\}$

$A_{4}=\left\{\left(u_{1}, 0\right),\left(u_{2}, 0\right),\left(u_{3}, 0.5\right),\left(u_{4}, 1\right),\left(u_{3}, 0.5\right), \ldots,\left(u_{n}, 0\right)\right\}$

$A_{n-1}=\left\{\left(u_{1}, 0\right), \ldots,\left(u_{n-3}, 0\right),\left(u_{n-2}, 0.5\right),\left(u_{n-1}, 1\right),\left(u_{n}, 0.5\right)\right\}$

$A_{n}=\left\{\left(u_{1}, 0\right), \ldots,\left(u_{n-2}, 0\right),\left(u_{n-1}, 0.5\right),\left(u_{n}, 1\right)\right\}$

Langkah 5. Memfuzzikan data histori. Langkah ini bertujuan untuk mendapatkan himpunan fuzzy yang sesuai untuk setiap data. Jika data time series yang diperoleh ada dalam interval $u_{k}$ untuk suatu $k$ maka data tersebut difuzzikan dalam himpunan fuzzy $A_{k}$.

Langkah 6. Menentukan relasi logik fuzzy dari nilai-nilai data, yaitu $A_{i} \rightarrow A_{k}$, yang berarti bahwa "jika nilai data $x$ adalah $A_{i}$ maka nilai data $x+1$ adalah $A_{k}$. $A_{i}$ disebut keadaan sekarang (anteseden) dan $A_{k}$ disebut keadaan selanjutnya.

Langkah 7. Membentuk kelompok relasi logik fuzzy dari data berdasarkan keadaan sekarang dari relasi logik fuzzy. Sebagai contoh, misalkan terdapat dua relasi logik fuzzy yang mempunyai anteseden yang sama, $A_{1} \rightarrow A_{l}$ dan $A_{1} \rightarrow A_{m}$, maka keduanya dikelompokkan dalan kelompok relasi logik fuzzy sebagai $A_{1} \rightarrow A_{l}, A_{m}$

Langkah 8. Menghitung output ramalan. Misalkan $F(t-1)=A_{j}$, ramalan dihitung berdasarkan aturan berikut: Aturan 1: Jika kelompok relasi logik fuzzy $A_{j}$ adalah kosong, yaitu $A_{j} \rightarrow \varnothing$, maka ramalan $F(t)$ adalah $m_{j}$ , yaitu titik tengah dari interval $u_{j}$ :

$$
F(t)=m_{j}
$$

Aturan 2: Jika kelompok relasi logik fuzzy $A_{j}$ adalah satu-ke-satu, yaitu $A_{j} \rightarrow A_{k} ; j, k=1,2, \ldots, n$; maka ramalan $F(t)$ adalah $m_{k}$, yaitu titik tengah dari interval $u_{k}$ :

$$
F(t)=m_{k}
$$

Aturan 3: Jika kelompok relasi logik fuzzy $A_{j}$ adalah satu-ke-banyak, yaitu $A_{j} \rightarrow A_{1}, A_{2}, \ldots, A_{n} ; j=1,2, \ldots, n$; maka ramalan $F(t)$ adalah nilai rata-rata dari $m_{1}, m_{2}, \ldots, m_{n}$, dimana $m_{1}, m_{2}, \ldots, m_{n}$ berturut-turut titik tengah dari interval $u_{1}, u_{2}, \ldots, u_{n}$ :

$$
F(t)=\frac{m_{1}+m_{2}+\ldots+m_{n}}{n}
$$

\section{CONTOH PENERAPAN}

Model peramalan time series fuzzy diilustrasikan dengan menggunakan data persentase konstribusi pengeluaran konsumsi rumah tangga terhadap PDRB kabupaten Majene, tahun 2010 sampai dengan 2019, seperti dalam Tabel 1.

Tabel 1 Peresentase konstribusi pengeluaran konsumsi rumah tangga terhadap PDRB Kabupaten Majene

\begin{tabular}{|c|c|}
\hline Tahun & Konstribusi Pengeluaran Konsumsi Rumah Tangga terhadap PDRB (\%) \\
\hline 2010 & 66,58 \\
\hline 2011 & 65,83 \\
\hline 2012 & 64,25 \\
\hline 2013 & 64,66 \\
\hline 2014 & 62,62 \\
\hline 2015 & 64,21 \\
\hline 2016 & 64,61 \\
\hline
\end{tabular}


https://jurnal.unsulbar.ac.id/index.php/saintifik

\begin{tabular}{|l|l|}
\hline 2017 & 62,91 \\
\hline 2018 & 61,64 \\
\hline 2019 & 60,34 \\
\hline
\end{tabular}

Sumber: BPS Kab. Majene (Kabupaten Majene dalam Angka)

Proses peramalan dengan time series fuzzy dilakukan dengan langkah-langkah seperti pada bagian 2, sebagai berikut:

Langkah 1: Menentukan nilai minimum $\left(\mathrm{D}_{\min }\right)$ dan maksimum $\left(\mathrm{D}_{\max }\right)$ dari data, yaitu $\mathrm{D}_{\min }=60,34 \%$ dan $\mathrm{D}_{\max }=$ $66,58 \%$.

Langkah 2: Dengan memilih dua bilangan tertentu $D_{1}=5,34$ dan $D_{2}=3,42$ maka diperoleh himpunan semesta $\mathrm{S}=[55,70]$.

Langkah 3: Dengan menggunakan aturan average based length, diperoleh 150 interval dengan panjang setiap interval adalah 0.1 ; yaitu $u_{1}=[55,55.1], u_{2}=[55.1,55.2], \ldots, u_{150}=[69.9,70]$.

Langkah 4: Mendefinisikan himpunan fuzzy $A_{i}$ yang merupakan nilai linguistik dari variabel linguistik "besarnya konstribusi pengeluaran konsumsi rumah tangga terhadap PRDB". Himpunan fuzzy $A_{i}$ pada semesta $\mathrm{S}$ adalah sebagai berikut:

$$
\begin{aligned}
A_{1}= & \left\{\left(1, u_{1}\right),\left(0.5, u_{2}\right),\left(0, u_{3}\right), \ldots,\left(0, u_{150}\right)\right\}, \\
A_{2}= & \left\{\left(0.5, u_{1}\right),\left(1, u_{2}\right),\left(0.5, u_{3}\right),\left(0, u_{4}\right), \ldots,\left(0, u_{150}\right)\right\} \\
A_{3}= & \left\{\left(0, u_{1}\right),\left(0.5, u_{2}\right),\left(1, u_{3}\right),\left(0.5, u_{4}\right),\left(0, u_{5}\right), \ldots,\left(0, u_{150}\right)\right\} \\
& \quad \cdots \\
A_{k}= & \left\{\left(0, u_{1}\right),\left(0, u_{2}\right), \ldots,\left(0.5, u_{k-1}\right),\left(1, u_{k}\right),\left(0.5, u_{k+1}\right),\left(0, u_{k+2}\right), \ldots,\left(0, u_{150}\right)\right\} \\
& \quad \ldots \\
A_{149}= & \left\{\left(0, u_{1}\right), \ldots,\left(0, u_{147}\right),\left(0.5, u_{148}\right),\left(1, u_{149}\right),\left(0.5, u_{150}\right)\right\} \\
A_{150}= & \left\{\left(0, u_{1}\right), \ldots,\left(0, u_{148}\right),\left(0.5, u_{149}\right),\left(1, u_{150}\right)\right\}
\end{aligned}
$$

Langkah 5: Memfuzzikan data historis, yaitu menentukan himpunan fuzzy yang sesuai dengan data historis, seperti dalam Tabel 2.

Tabel 2 Fuzzifikasi data historis

\begin{tabular}{|c|c|c|}
\hline Tahun & $\begin{array}{c}\text { Konstribusi Pengeluaran } \\
\text { Konsumsi Rumah Tangga } \\
\text { terhadap PDRB (\%) }\end{array}$ & Fuzzifikasi \\
\hline 2010 & 66,58 & $A_{116}$ \\
\hline 2011 & 65,83 & $A_{109}$ \\
\hline 2012 & 64,25 & $A_{93}$ \\
\hline 2013 & 64,66 & $A_{97}$ \\
\hline 2014 & 62,62 & $A_{77}$ \\
\hline 2015 & 64,21 & $A_{93}$ \\
\hline 2016 & 64,61 & $A_{77}$ \\
\hline 2017 & 62,91 & $A_{80}$ \\
\hline 2018 & 61,64 & $A_{67}$ \\
\hline 2019 & 60,34 & $A_{54}$ \\
\hline
\end{tabular}

Langkah 6: Menentukan relasi logik fuzzy dan kelompok relasi logik fuzzy dari data historis, seperti pada Tabel 3 dan Tabel 4 berikut: 
https://jurnal.unsulbar.ac.id/index.php/saintifik

Tabel 3 Relasi Logik Fuzzy data histori

\begin{tabular}{|c|}
\hline Relasi Logik Fuzzy \\
\hline$A_{54} \rightarrow \varnothing$ \\
\hline$A_{67} \rightarrow A_{54}$ \\
\hline$A_{77} \rightarrow A_{80}$ \\
\hline$A_{77} \rightarrow A_{93}$ \\
\hline$A_{80} \rightarrow A_{67}$ \\
\hline$A_{93} \rightarrow A_{77}$ \\
\hline$A_{93} \rightarrow A_{97}$ \\
\hline$A_{97} \rightarrow A_{77}$ \\
\hline$A_{109} \rightarrow A_{93}$ \\
\hline$A_{116} \rightarrow A_{109}$ \\
\hline
\end{tabular}

Tabel 4 Kelompok Relasi Logik Fuzzy

\begin{tabular}{|c|c|}
\hline Kelompok & Relasi Logik Fuzzy \\
\hline 1 & $A_{54} \rightarrow \varnothing$ \\
\hline 2 & $A_{67} \rightarrow A_{54}$ \\
\hline 3 & $A_{77} \rightarrow A_{80}, A_{93}$ \\
\hline 4 & $A_{80} \rightarrow A_{67}$ \\
\hline 5 & $A_{93} \rightarrow A_{77}, A_{97}$ \\
\hline 6 & $A_{97} \rightarrow A_{77}$ \\
\hline 7 & $A_{109} \rightarrow A_{93}$ \\
\hline 8 & $A_{116} \rightarrow A_{109}$ \\
\hline
\end{tabular}

Langkah 7: Defuzzifikasi himpunan fuzzy, yaitu menentukan nilai anteseden $A_{j}$ pada setiap kelompok logik fuzzy dengan menggunakan aturan 1, 2, dan 3 pada bagian 2, seperti pada Tabel 5 berikut:

Tabel 5 Nilai defuzzifikasi

\begin{tabular}{|c|c|}
\hline Anteseden & Nilai \\
\hline$A_{54}$ & 60.35 \\
\hline$A_{67}$ & 60.35 \\
\hline$A_{77}$ & 63.6 \\
\hline$A_{80}$ & 61.65 \\
\hline$A_{93}$ & 63.65 \\
\hline$A_{97}$ & 62.65 \\
\hline$A_{109}$ & 64.25 \\
\hline$A_{116}$ & 65.85 \\
\hline
\end{tabular}

Langkah 8: Menentukan nilai ramalan tiap data historis. Berdasarkan Tabel 2, 3, 4 dan 5, nilai ramalan konstribusi pengeluaran konsumsi rumah tangga terhadap PDRB dapat dihitung. Berikut ini diberikan proses perhitungan peramalan tahun 2011 sampai dengan 2019.

[2011]: Fuzzifikasi nilai data tahun 2011 dalam Tabel 2 adalah $A_{116}$, dan dari Tabel 4, relasi logic fuzzy $A_{116}$ adalah $A_{116} \rightarrow A_{109}$, sehingga nilai anteseden $A_{116}$ dapat diperoleh dari Tabel 5, yaitu 65.85. Jadi nilai ramalan untuk tahun 2011 adalah $65.85 \%$.

Dengan cara yang sama, nilai ramalan untuk tahun 2012 sampai dengan 2020 dapat dihitung seperti diperlihatkan dalam Tabel 6.

Dari Tabel 6, diperoleh, nilai ramalan konstribusi pengeluaran konsumsi rumah tangga terhadap PDRB dari tahun 2011 sampai dengan 2020. Rentang error ramalan adalah $0 \%$ sampai dengan $1.48 \%$ dengan rata-rata error atau nilai MAPE adalah $0.59 \%$.

Tabel 6 Data aktual, nilai ramalan dan error ramalan

\begin{tabular}{|c|c|c|c|}
\hline Tahun & $\begin{array}{c}\text { Data Aktual Konstribusi } \\
\text { Pengeluaran Konsumsi Rumah } \\
\text { Tangga terhadap PDRB (\%) }\end{array}$ & $\begin{array}{c}\text { Data Ramalan Konstribusi } \\
\text { Pengeluaran Konsumsi Rumah } \\
\text { Tangga terhadap PDRB (\%) }\end{array}$ & $\begin{array}{c}\text { Error } \\
\text { Ramalan }\end{array}$ \\
\hline 2010 & 66.58 & - & - \\
\hline 2011 & 65.83 & 65.85 & 0.000304 \\
\hline
\end{tabular}


https://jurnal.unsulbar.ac.id/index.php/saintifik

\begin{tabular}{|c|c|c|c|}
\hline 2012 & 64.25 & 64.25 & 0 \\
\hline 2013 & 64.66 & 63.65 & 0.01562 \\
\hline 2014 & 62.62 & 62.65 & 0.000479 \\
\hline 2015 & 64.21 & 63.6 & 0.0095 \\
\hline 2016 & 64.61 & 63.65 & 0.014858 \\
\hline 2017 & 62.91 & 63.6 & 0.010968 \\
\hline 2018 & 61.64 & 61.65 & 0.000162 \\
\hline 2019 & 60.34 & 60.35 & 0.000166 \\
\hline $\mathbf{2 0 2 0}$ & - & $\mathbf{6 0 . 3 5}$ & \\
\hline & & & $\begin{array}{c}\text { MAPE= } \\
\text { 0.59\% }\end{array}$ \\
& & & \\
\end{tabular}

Gambar 1 Kurva data aktual dan nilai ramalan dari model time series fuzzy

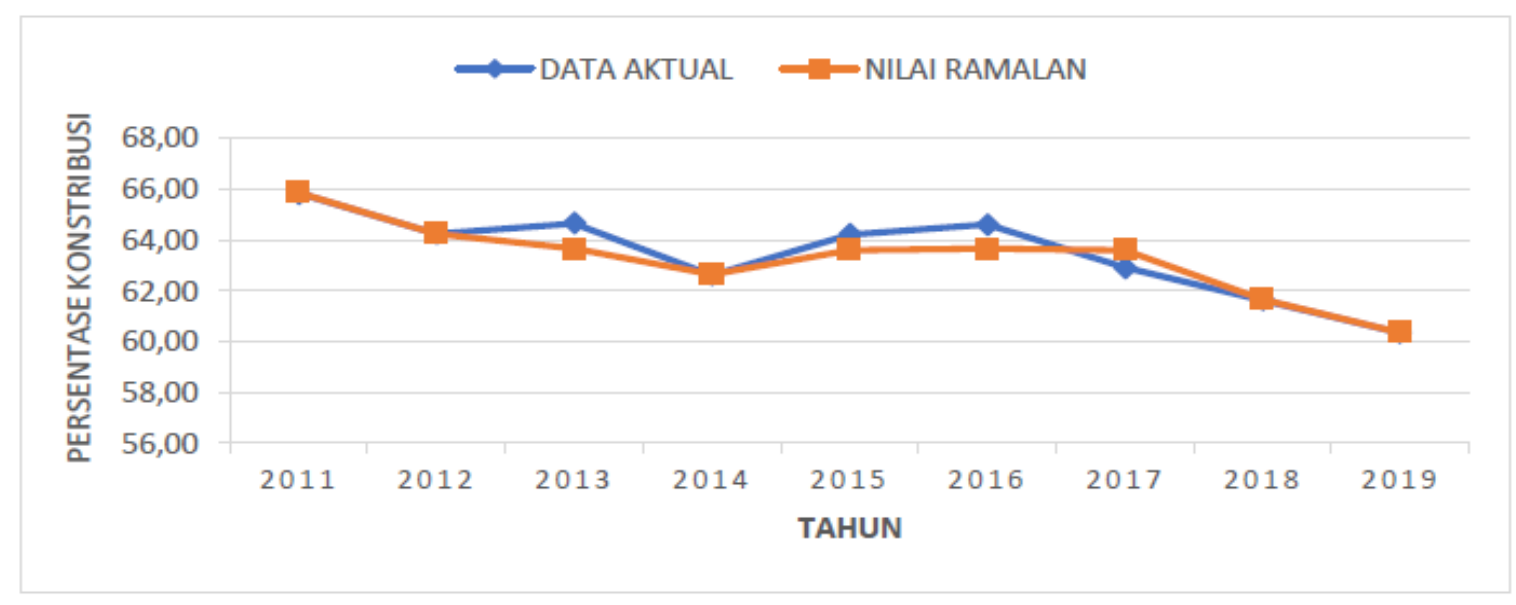

\section{DAFTAR PUSTAKA}

Basyigit, A. I, Ulu, C, Guzelkaya, M, 2014, A New Fuzzy Time Series Model using Triangular and Trapezoidal Membership Function, Proceeding ITISE 2014 Granada 25 - 27 Juni 2014, p.634 - 644.

BPS Kab. Majene, 2020, KABUPATEN MAJENE DALAM ANGKA MAJENE REGENCY in Figures 2020, ISBN: 978-602-6446-67-1

C.H. Cheng, T.L. Chen \& C.H. Chiang, 2006, Trend-weighted fuzzy time series model for TAIEX forecasting, ICONIP, Part III, LNNC 4234, 469-477.

C.H.L. Lee, A. Liu \& W.S. Chen, 2006, Pattern Discovery of Fuzzy time series for financial prediction, IEEE Transactions on Knowledge and data Engineering, 18, p.613-625.

H-K. Yu, 2005, Weighted fuzzy time series models for Taiex forecasting, Physica A, 349, 609-624.

H.H Chu, T.L. Chen, C.H. Cheng \& C.C., 2009, Huang, Fuzzy dual-factor time series for stock index forecasting, Expert Systems with Applications, 36, p.165-171.

K. Huarng, 2001, Heuristic models of fuzzy time series for forecasting, Fuzzy Sets and Systems, 123, p.369386. 
https://jurnal.unsulbar.ac.id/index.php/saintifik

K. Huarng, Tiffany H-K Yu \& Yu W-S, 2007, A multivariate heuristic model for fuzzy time series forecasting, IEEE Transactions on Systems, Man, and Cybernetics, 37, p.263-275.

Lee, M. H, Efendi, R, Ismail, Z., 2009, Modified Weighted for Enrollment Forecasting Based on Fuzzy Time Series, MATEMATIKA, Volume 25, Number 1, 67-78

Mutalib, S. M, Ramli, N, Daud, M, 2018, Forecasting Fuzzy Time Series Model based on Trapezoidal Fuzzy Numbers with Area and Height Similarity Measure Concept, AIP Conference Proceeding 1974.

Q, Song \& B. S. Chissom, 1993, Forecasting Enrolments with Fuzzy Time Series - Part I, Fuzzy Sets and Systems 54, 1-9.

Ramli, N, Mutalib, S. M, Daud, M, 2018, Fuzzy Time Series Forecasting Model based on Center of Gravity Similarity Measure, Journal of Computer Science \& Computational Mathematics, 8(4), p.121 - 124.

S.M. Chen, 2000, Temperature prediction using fuzzy time series, IEEE Transactions on Systems, Man, and Cybernetics, 30, p.263-275.

S.M. Chen, 1996, Forecasting enrolments based on fuzzy time series, Fuzzy Sets and Systems, 81, p.311-319.

Tsaur, R. C, 2012, A Fuzzy Time Series-Markov Chain Model with an Application to Forecast the Exchange Rate between the Taiwan and US Dollar, International Journal of Innovative Computing, Information and Control, vol. 8, No. 7, p.4931 - 4942.

T.A Jilani \& S.M.A. Burney, 2008, A refined fuzzy time series model for stock market forecasting, Physica A, ScienceDirect, 387, p.2857-2862.

T.H.K. Yu \& K.H. Huarng, 2008, A bivariate fuzzy time series model to forecast the TAIEX, Expert Systems with Application 34, 2945-2952.

Xihao, S and Yimin, L., 2008, Average Based Fuzzy Time Series Models for Forecasting Shanghai Compound Index, World Journal of Modelling and Simulation, 4(2), $104-111$. 